Sujetos y subjetividades docentes en las políticas públicas argentinas. El ejemplo del pensamiento pedagógico latinoamericano. Parte 2

Cintia Rogovsky

Question, Vol. 1, N.․ 57, e026, enero-marzo 2018. ISSN 1669-6581

http://perio.unlp.edu.ar/ojs/index.php/question/article/view/4440

FPyCS | Universidad Nacional de La Plata

La Plata | Buenos Aires | Argentina

Recibido: 31-10-2017 Aceptado: 15-11-2017

Cita sugerida: Rogovsky, C. (2018). Sujetos y subjetividades docentes en las políticas públicas argentinas. El ejemplo del pensamiento pedagógico latinoamericano. Parte 2. Question, 1(57), e026. doi: https://doi.org/10.24215/16696581e026

\title{
Sujetos y subjetividades docentes en las políticas públicas argentinas. El ejemplo del pensamiento pedagógico latinoamericano. Parte 2
}

\author{
Subjects and teaching subjectivities in Argentine public policies. The \\ example of Latin American pedagogical thought. Part 2
}

\section{Cintia Rogovsky}

Universidad Nacional de La Plata (Argentina) crogovsky@gmail.com

\section{Resumen}

El análisis de los dispositivos de formación y capacitación docente en las políticas públicas permite observar indicios de las posibles implicancias del nuevo proyecto político pedagógico y comunicacional gubernamental iniciado en diciembre de 2015, desde la perspectiva de la comunicación/educación en la construcción de nuevas subjetividades docentes. Por medio del ejemplo del módulo Pensamiento Pedagógico Latinoamericano desarrollado entre 2014 y 2017 en el Programa Nacional de Formación Permanente "Nuestra Escuela" del Instituto Nacional de Formación Docente del Ministerio de Educación de la Nación en las 24 provincias argentinas, se pretende observar eliminaciones de contenidos, rupturas e interrupciones de procesos 
federales de capacitación que revelan tramas, discursos y prácticas autoritarias, desplegadas en la modalidad virtual en este caso, así como posibles consecuencias de estas nuevas subjetividades pedagógicas en dinámicas de individuación "narcisistas" y "autistas" acordes al discurso instrumental de la "sociedad de la transparencia" y en tensión con proyectos colectivos comunes. Este trabajo forma parte de las investigaciones para la tesis doctoral en Comunicación en la Facultad de Periodismo y Comunicación Social.

Palabras clave: Comunicación; programas de educación; profesión docente; pensamiento latinoamericano; subjetividades.

\section{Abstract}

The analysis of the training devices and teacher training in public policies allows to observe indications of the possible implications of the new governmental pedagogical political and communicational project initiated in december of 2015, from the perspective of communication / education in the construction of new teacher subjectivities.

Through the example of the module Latin American Pedagogical Thinking developed between 2014 and 2017 in the Program National of Permanent Formation "Nuestra Escuela" (Our School) of the National Institute of Teacher Training of the Ministry of Education of the Nation in the 24 Argentine provinces, aims to observe eliminations of contents, ruptures and interruptions of federal processes of training that reveal plots, speeches and practices authoritarian, deployed in the virtual modality, as well as possible consequences of these new pedagogical subjectivities in dynamics of individuation in tension with collective projects according to the instrumental discourse of the "society of transparency". This work is part of the research for the doctoral thesis in Communication in the Facultad de Periodismo y Comunicación Social.

Keywords: Communication; educational programs; teaching profession; Latin American thought; subjectivities.

\section{Discursos mediáticos y formación docente en tiempos de zombis y androides}

En la primera parte del artículo reflexionamos acerca de cuestiones que contextualizan este ensayo en torno a la hipótesis de que los dispositivos de formación, capacitación y 
profesionalización docente en las políticas públicas forman parte de la trama del campo comunicación/educación e inciden en la configuración de subjetividades docentes.

En muchos maestros y profesores que quizá no leyeron a Jesús Martín-Barbero ni teorías de comunicación/educación es posible reconocer, sin embargo, sus huellas en algunos saberes del enseñar que las políticas del Instituto Nacional de Formación Docente (INFD) y luego, del Programa Nacional de Formación Permanente "Nuestra Escuela" (PNFP) permitieron desplegar, y a la vez, alimentaron. En este dispositivo Jorge Huergo jugó un rol fundamental, tanto por el trabajo en los institutos de la provincia de Buenos Aires, entre 2005 y 2007, cuando coordinó en los diseños curriculares para la formación docente (2), como en la incorporación del pensamiento político y pedagógico latinoamericano en los seminarios del INFD que fueron la base para el módulo de Pensamiento Pedagógico Latinoamericano (PPL), incorporado como contenido transversal a 10 de las 14 Especializaciones de postitulación desarrolladas entre 2014 y 2016 y que hoy, lamentablemente, están llegando a su ocaso.

Estos educadores son protagonistas de diversos modos de hacer escuela, que expresan (en algunos casos padecen, en otros disfrutan, en la mayoría, posiblemente ambas cosas) la complejidad de educar en el mundo contemporáneo. Es probable que algunos sean conscientes de que su su tarea se produce en un campo donde la deslocalización y desterritorialización del conocimiento (Martín-Barbero, 2003) pincelan el cotidiano. Muchos se han formado en este modelo y entienden el impacto que las TIC tienen en los modos de enseñar y aprender, de construir subjetividades donde la mediación pedagógica se resignifica.

Asimismo, más allá de mitos educativos y diversas tradiciones, aparecen nuevos problemas en la trama de construcción de identidades del sujeto docente, pues en la sociedad contemporánea, tan compleja como a veces confusa, se despliegan "nuevas dinámicas de individuación" (Merklen, 2016: 338) que están poniendo en crisis la vida en común y los proyectos colectivos, como es y pretende ser la educación pública desde los tiempos fundacionales sarmientinos. En tanto habitantes de la gran aldea global en la que el mundo parece haber devenido no escapan a la seducción y afectación que produce la maquinaria del poder del capitalismo en su fase actual y en su producción de subjetividades, que lleva a los individuos a auto percibirse y comportarse como empresas, explotándose a sí mismos, desvalorizando o rompiendo los lazos con otros, entregándose sumisamente a los encantos de estas nuevas formas de dominación de los amos. Más hoy, cuando al parecer, no surgen alternativas -parece no haber otro- al gran seductor neoliberal. Aun así, siempre nos queda la lengua,

Nuestra experiencia de lo Común es la copertenencia al surgimiento en la lengua, siempre fallido, en falta y tentado por las diversas promesas imaginarias de "autovalorizarnos" de tal modo que la verdad de nuestra fragilidad constitutiva se esconda para nosotros mismos. He 
aquí, a nuestro juicio, uno de los secretos que brindan su fuerza a la promesa del imaginario neoliberal (Alemán, 2017).

La alfabetización y la lengua conforman pilotes estratégicos de la escolarización, de la formación y capacitación docente y las prácticas de enseñanza-aprendizaje en sus diversas expresiones y modalidades. Además se ha incorporado fuertemente en los últimos años el uso de TIC y la modalidad virtual, sosteniendo al mismo tiempo la idea de lo común y colectivo para hacer comunidad, imbricada con la aspiración a construir sociedades menos desiguales donde la creencia predominante es que la educación ocupa un lugar central para la integración y configuración de la identidad nacional. Sin embargo, esta realidad no se refleja en las representaciones que proponen la mayoría de los discursos mediáticos hegemónicos que con frecuencia sugieren, en sintonía con los discursos de muchas autoridades gubernamentales en distintas jurisdicciones, gramáticas que sugieren, por ejemplo: la necesidad de "innovar en la capacitación", como equivalente a "entrenar" (to coach) a los docentes en el uso de TIC que, en verdad, ya han incorporado hace muchos años al trabajo áulico e institucional, ayudados en gran medida por el conjunto de políticas públicas que favorecieron ese grado de inclusión digital y tecnológica de la década pasada. Esas políticas, además, requieren de fuertes inversiones y un financiamiento sostenido que ha decaído notoriamente en los últimos dos años.

Por otro lado, el enredo discursivo y la falta de diálogo con los especialistas, equipos y docentes que han transitado estas experiencias puede llevar a confundir el uso de TIC o de modalidades de enseñanza en la virtualidad con un cambio de paradigma en los vínculos de enseñanza aprendizaje, donde lo que ocurre es siempre distinto y algo más de lo pautado, planificado y normado. Es decir, algo siempre escapa al control del dispositivo del tecno-poder. Como en una distopía de Philip Dick o Margaret Atwood, el dispositivo de capacitación considera a maestros y profesores como mamíferos evolucionados con cerebros complejos plausibles de ser intervenidos -desde perspectivas didácticas asociadas a una perspectiva sesgada de las neurociencias- y una temporalidad sin pasado ni prospectiva, como los perros, o mejor aún, los lobos de los lobos, que al parecer no tienen memoria ni planifican, o directamente, los androides o zombis y no como humanos que nos educamos unos a otros sociedad, en la cultura e inscriptos en la historia. En esos enunciados de formadores de opinión existe, cuanto menos, un profundo desconocimiento -o prejuicios- respecto de las realidades de las educación pública argentina, de la que, por lo general, sólo se acuerdan en la agenda mediática en la campaña electoral, cuando se discuten salarios con medidas de fuerza $u$ ocurren hechos de violencia-espectáculo que afectan a las comunidades escolares. El fetiche "educacionista" (De Alba) se esgrime en todos los discursos de campaña, como si la palabra 
educación fuera un significante mágico desvinculado de los problemas filosóficos, religiosos, pedagógicos, políticos y del financiamiento.

\section{No contaminados por la idea de Estado}

¿Por qué ocurre esto? Una primera hipótesis es que tal vez son discursos elaborados -a la vez que configurantes- por un sujeto político que no ha transitado la escuela pública (3), de modo que construye enunciados a partir de imaginarios y supuestos de sus propios habitus y matrices ideológicas, alimentados por los confusos nutrientes que propone a diario la hipercomunicación e hiperinformación global. La mezcla de estos ingredientes, desprovista de herramientas de análisis crítico y conocimientos del campo incluye el agregado de que el edificio de este nuevo constructo está sostenido por objetivos y criterios más o menos explícitos de la "razón empresarial". Entonces, la ecuación costo/beneficio disputa sentidos con las de cualquier otro proyecto político- pedagógico (construir lo común; la felicidad del pueblo y la grandeza de la nación; una ciudadanía unida; emancipar a los pueblos latinoamericanos; disminuir la violencia y las prácticas discriminatorias; mejorar la calidad de la enseñanza con inclusión social y menos desigualdades, producir conocimientos que beneficie al conjunto de la población y promueva el desarrollo nacional), produce conclusiones temerarias que podrían en muchos casos resultar risueñas sino tuvieran consecuencias, en ocasiones nefastas, sobre la vida de tantos ciudadanos y ciudadanas. Tal es el caso, por ejemplo, de la formación de grado y posgrado (cuando esta existe) de algunos cuadros de la conducción del gobierno nacional, que ha transcurrido en instituciones extranjeras o nacionales privadas destinadas a las elites con alto poder adquisitivo.

Se trata de equipos que no han estado "expuestos a la idea de Estado" (Gessaghi, 2016: 89), y conciben a las instituciones públicas y sus prácticas a partir de construcciones discursivas que implican ajenidades, prejuicios y rechazos propios de sus orígenes y matrices culturales, su identidad y pertenencia -en algunos casos, en realidad, se trata de una identificación aspiracional- como "clases altas". Eso posiblemente impacte en gran medida en sus discursos y prácticas comunicativas, en la dificultades para establecer diálogos fecundos con los equipos técnico-pedagógicos formados en el sistema de educación superior público (ISFD, universidades nacionales, Conicet y otros), en el desconocimiento o desapego por la legislación (surgida de complejos procesos políticos de construcción de consensos sociales con múltiples actores) y en el diseño de las políticas públicas y, sobre todo, en el proyecto político para la formación y capacitación docente, que es un componente estratégico de la educación pública. Por momentos, se tiene la sensación de que no existe un universo 
vocabular común, que se hablan "en distintos idiomas" o de hablarle a las paredes, como diría Lacan.

Retorna el concepto de extrañamiento de los formalistas rusos, pero con un sentido algo mutado. Si en su origen este refiere a que mostrar el objeto (artístico, en este caso) fuera de su ámbito acostumbrado, al sustraerlo de lo cotidiano, se produce un extrañamiento (el famoso inodoro de Duchamp), lo traigo aquí para nombrar al conjunto de pensamientos, emociones y acciones que provoca en muchos docentes y equipos técnico-pedagógicos la irrupción de estos sujetos políticos portadores de un discurso netamente empresarial en ámbitos de gestión educativa, de producción de políticas públicas y de proyectos de formación y capacitación.

A este extrañamiento se agregan matices que complejizan aun más la cuestión, puesto que algunos funcionarios que asumen la conducción de áreas educativas históricamente -y más allá de los distintos signos políticos y objetivos- en manos de personas formadas y vinculadas a la educación pública de diversos modos (en investigación, trayectoria por el sistema, ejercicio de la docencia en distintos niveles) vienen de un mundo no "expuesto a la idea de Estado" (Gesaghi, 2016): la educación superior privada, en instituciones (fundaciones, ONG) privadas extranjeras vinculadas al marketing, la administración de empresas, la publicidad o, en muchos casos, una combinación entre gestión estatal y privada.

A eso se agrega que muchos carecen de formación en carreras ligadas a la educación o a la comunicación. ¿Es posible pensar esto no sólo como un problema político sino como un problema de comunicación/educación estratégico en una sociedad democrática que parece no poder encontrar canales institucionales adecuados para la tramitación de los conflictos educativos o los proyectos político-pedagógicos en disputa? Al fracasar los canales de diálogo se recurre a la imposición autoritaria y unilateral de cambios estructurales en el sistema de formación y capacitación docente (y en la educación en general) mediante decretos, resoluciones, disposiciones del poder ejecutivo que barren con el andamiaje de normativas y articulaciones surgidas en los ámbitos previstos, incluso, por la CNA y las constituciones provinciales.

\section{Jorge Huergo y el módulo Pensamiento Pedagógico Latinoamericano (PPL)}

La incorporación de la perspectiva comunicación/educación en 10 Postítulos -y de equipos de formadores provenientes del campo comunicacional- a un programa masivo y federal de semejante impacto no podía darse sin tensiones, sin reactualizar debates respecto a la cuestión de las incumbencias disciplinares y epistemológicas, tanto hacia el interior del campo educativo como hacia otras externalidades. Del mismo modo que algunas perspectivas de la educación superior universitaria tienden a invisibilizar los aportes de la formación docente que 
se desarrolla en los Institutos Superiores de Formación Docente (ISFD) en las provincias, otras corrientes han luchado para articular la educación superior universitaria y terciaria. El hecho de que el módulo PPL, en sus distintas versiones escritas o adaptadas por distintos autores a partir de la metáfora utilizada por Huergo de que "el pedagogo es el viaje", invitó a cientos de miles de cursantes a preguntarse acerca del sujeto pedagógico latinoamericano actual, (4) a interpelar sus prácticas áulicas, a reconocer los saberes de los educadores como saberes transformadores que deben incorporarse y entrar en diálogo en las currículas oficiales. No se trataba de un enfoque histórico de la educación latinoamericana -si bien se historizaban las pedagogías propuestas- sino de un enfoque de comunicación/educación que, por ejemplo, al recuperar la experiencia de la actual legislación educativa boliviana (sancionada en 2010, tras la consideración de Bolivia como estado plurinacional y multilingüe) y sus implicancias, recuperaba la experiencia de la escuela indigenal de Warisata, desarrollada por Elizardo Pérez y Avelino Siñani entre 1930 y 1940. De ningún modo las experiencias pedagógicas se repiten, tampoco se buscaba una evocación nostálgica o romántica, sino indagar allí cuestiones como la vinculación entre la perspectiva pedagógica teórica, que mira a la educación en su conjunto y complejidad, y la didáctica, que hace foco en las prácticas; o los procesos de enseñanza y aprendizaje de la escritura, para trabajar en aulas con niños y niñas que hablan en distintas lenguas o cuyas familias son inmigrantes, como ocurre en muchas escuelas del país. Se buscó así propiciar el reconocimiento de la alteridad y de los diversos universos culturales del estar siendo latinoamericanos, los vínculos entre proyecto educativo y proyecto político, las tramas de construcción de hegemonía en los sistemas escolares.

PPL, al igual que antes el seminario, formulaba algunas interpelaciones que, en el dispositivo del PNFP, producen incomodidades. Partía de supuestos epistemológicos y posicionamientos explicitados: reconocer los vínculos entre educación, ética y política; entre proyectos políticopedagógicos y proyectos económico-sociales; las relaciones de poder en la institucionalidad escolar, del sistema y de los vínculos pedagógicos, pero también en los discursos y las prácticas y las culturas populares latinoamericanas. Intentaba poner en debate las rupturas y continuidades en los procesos político-pedagógicos y también hacía foco en las interrupciones de las luchas emancipadoras causadas por los golpes, las dictaduras y los procesos neoliberales. La propuesta buscaba resignificar el valor de algunas tradiciones pedagógicas oficiales $y$ otras de fuentes populares latinoamericanas, a la vez que procuraba reflexionar, en diálogo con los y las cursantes así como con otros espacios curriculares en cada Postítulo, respecto a los sentidos de esos discursos pedagógicos, (5) por lo general ausentes o invisibilizadas en el océano de la "hiperinformación" que tiende a obturar el pensamiento crítico en favor de la doxa, dándole a la comunicación y a la educación un sentido instrumental y mercantil (Byung-Chul Han, 2013, 17). A partir de articular con otros módulos de las 10 Especializaciones en las que estaba incorporado desde 2014, PPL ponía a disposición de los 
docentes diversas experiencias (incluyendo las de cursantes de cuatrimestres anteriores) que mostraban múltiples posibilidades de las pedagogías en clave emancipatoria, de la comunicación popular incorporada a la educación popular, de las resistencias y modos de hacer escuela en clave de justicia social y desde una perspectiva de derechos humanos, de crítica al patriarcado, de repudio a la guerra y a la violencia, de respeto a la alteridad. Además, en los aspectos didácticos y evaluativos, promovía por parte de los cursantes la escritura regular de sus saberes y experiencias.

¿Qué detectaron en esta propuesta las nuevas autoridades educativas nacionales, que puso rápidamente en marcha mecanismos de interrupción, supresión o censura? Por lo pronto, lo que quedó a la vista fue la supresión de PPL, luego de unos meses donde se presionó a los equipos de contenidistas, para reformular sus perspectivas, eliminar determinada bibliografía (autores clásicos y consagrados de la pedagogía que gozan de reconocimiento nacional e internacional, pero son críticos del neoliberalismo, por ejemplo) o de ciertos contenidos característicos de la investigación pedagógica latinoamericana de las últimas décadas; la supresión de temáticas como las pedagogías vinculadas a Teología de la Liberación y el peronismo; así como la propuesta de retornar viejas teorías del campo científico o médico. Se planteó además la necesidad de evitar encuentros multidisciplinares de los equipos donde se generaban espacios de debate, con el argumento del temor a que se susciten reclamos salariales o de continuidad laboral propios de la vida democrática. Esto último configura una señal de la dificultad de la actual gestión del INFD para admitir las disidencias como parte de la vida institucional y cierta tendencia autoritaria. En consecuencia, y aunque los argumentos (o excusas) esgrimidos fueron diversos, la sospecha es que la perspectiva de comunicación/educación latinoamericanista sostenida allí ponía en confrontación el discurso meritocrático, instrumental y tecnocrático que intentan como parte de una concepción educacionista y de mercantilización de la educación. En el fondo de estos argumentos, flota además el fantasma del desfinanciamiento de la educación pública, que se corporiza en la subejecución del presupuesto educativo (2016) así como en el proyecto de presupuesto para la administración pública nacional presentado por el gobierno el último septiembre ante el Congreso. Pero también surgen otros interrogantes: ¿es posible sospechar la emergencia una gramática de la "transparencia" en el sentido de negar la alteridad, la diferencia, es decir, como propone Byung-Chul Han, como "un infierno de lo igual" (2013)? ¿Se trata de una exaltación en clave de "transparencia", cada vez menos reflexiva, acerca del propio dispositivo de hipercomunicación -la plataforma, las mediaciones, las herramientas digitales- sin la posibilidad del debate acerca de los contenidos, sin los tiempos e incluso, sin los espacios ni la disposición a transitar los conflictos que implica cualquier construcción colectiva de conocimientos, cualquier programa que se desarrolle en instituciones de tal magnitud y a esa escala? 


\section{Historia no natural de la destrucción}

En febrero de 2016 se destruye la transversalidad de PPL y de este modo se rompe esa magnífica oportunidad de diálogo colectivo e interdisciplinar en múltiples espacios formativos con el pensamiento pedagógico latinoamericano. El mes siguiente se elimina por completo el módulo en los Postítulos de Enseñanza de las Matemáticas para la Escuela Primaria y Secundaria y en Políticas Socioeducativas (5). Se discontinúan, o directamente se suprimen, los encuentros presenciales de los equipos de Coordinadores Académicos con los Coordinadores de Módulos, tutores, responsables de contenidos, especialmente ricos en prácticas comunicacionales que promueven intercambios y debates necesarios para mejorar el desarrollo del programa. En paralelo, se demandan a los equipos de formadores la implementación sistemática de diversas herramientas operativas para medir, controlar y evaluar aspectos administrativos y no pedagógicos: planillas Excel para controlar entradas diarias a la plataforma, monitoreo de cada clic de ingreso, permanencia y sitios que recorren los cursantes dentro de la plataforma; se planifica el uso del tiempo con sistemas similares a los que usan en las empresas, entre otras, mientras que se reduce el tiempo de lectura de los materiales bibliográficos y multimediales, de discusión y escritura de los contenidos de las clases, bibliografía, selección de materiales, edición, difusión de herramientas didácticas y de evaluación específicas y situadas, que irán siendo reemplazadas por otras normatizadas y generales. ¿Se trata de una mutación de la tarea pedagógica (incluso la evaluativa) hacia una tecnificación de herramientas para medir "rendimientos" con sentidos ajenos a los procesos de enseñanza-aprendizaje?

Esta tendencia a producir y acumular información en detrimento de procesos de comunicación/educación dialógicos en la formación docente no sólo se vincula a la necesidad de la gestión actual de reducir el presupuesto educativo, en este caso, de la capacitación docente, en aras de promover cursos de fundaciones y ONG privadas, como han denunciado en varias oportunidades los sindicatos de trabajadores de la educación y en particular el Colectivo de Trabajadores Virtuales nucleados en Ate. Además, la fragmentación de contenidos integradores, como el caso de PPL, facilita la desconexión de los equipos en los distintos trayectos formativos postitulares.

Un aumento de información y comunicación no esclarece por sí solo el mundo. La transparencia tampoco hace clarividente. La masa de información no engendra ninguna verdad. Cuanta más información se pone en marcha, tanto más intrincado se hace el mundo. La hiperinformación y la hipercomunicación no inyectan ninguna luz en la oscuridad (Byung Chul-Han, 2013: 79). 
Este proceso se irá desarrollando en lo que, hipotetizamos, puede inscribirse en ese clima general en el que el discurso sobre lo público se encuentra dominado por el lema que propone la "sociedad de la transparencia", donde las cosas "abandonan cualquier negatividad, cuando se alisan y allanan, cuando se insertan sin resistencia en el torrente liso del capital, la comunicación y la información. Las acciones se tornan transparentes cuando se hacen operacionales, cuando se someten a los procesos de cálculo, dirección y control" (Byung-Chul Han, 2013: 12).

¿Hay lugar para módulos como PPL si el proyecto político-pedagógico se constituye como dispositivo que promueve esta sociedad de la transparencia, que niega la profundidad, que no puede detenerse a reflexionar, observar, escuchar lo diferente, aquello justamente que es casi la esencia de los vínculos pedagógicos, del encuentro humanizante entre alteridades? Un dispositivo que exalta la velocidad y la inmediatez, posible por las tecnologías, y que además, instala un tipo de vínculo casi pornográfico entre los sujetos con la imagen, ¿no es acaso una sociedad uniformada, el sueño de todos los totalitarismos? Por otra parte, las prescripciones político-pedagógicas propias de la institucionalidad que comprendía el PNFP, con sus distintos elementos, fueron configurando entre 2012 y 2017 un "espacio de instalación" (Groys, 2016: 139). Produjeron adecuaciones en el nivel central nacional del sistema de capacitación docente, una arquitectura legal sólida y prospectiva; el desarrollo de procesos de organización originales, complejos, vertiginosos -incluyendo desde el financiamiento hasta las modalidades contractuales de los formadores y formadoras-, y en algunos casos, algo débiles (6). Por otra parte, difícilmente hubiera podido hacerse de otro modo, considerando los componentes, entre los cuales pueden mencionarse:

\section{Innovadores:}

a. Enseñanza y aprendizaje en modalidad casi exclusivamente virtual en una plataforma en la que pasaron de conectarse en pocos meses unos cinco mil usuarios a 300 mil aproximadamente.

b. Uso de herramientas de comunicación digitales en desarrollo o que se fueron aprendiendo y aprehendiendo mientras se recorrían los diferentes trayectos formativos.

c. Integración de equipos conformados por profesionales provenientes de campos disciplinares diversos y radicados en distintos lugares del país interactuando en la virtualidad.

d. Participación de universidades nacionales y sindicatos docentes, además de los gobiernos provinciales.

2. Inclusivos:

a. Accesible a todos los docentes en ejercicio de cualquier nivel y modalidad del país. En el caso del postítulo Políticas Socioeducativas se aceptaron cursantes de la educación no formal. 
b. Incorporación de especializaciones y contenidos curriculares históricamente ausentes en la formación y capacitación docente federal masiva, como pensamiento pedagógico latinoamericano; derechos humanos, entre otros. Justamente estos son los primeros contenidos que serán eliminados o modificados restringiendo la libertad de cátedra y objetando autores o contenidos.

A su vez, se trata de dispositivos relativamente nuevos, pero cuyos actores y vínculos están condicionados por habitus propios de las prácticas institucionales de enseñanza en modalidades presenciales. En consecuencia, las tensiones entre los equipos cuya actividad está más ligada a lo técnico con quienes se centran en los contenidos pedagógicos pueden expresar también las disputas entre lógicas pedagógicas y de trabajo distintas.

En algunos casos, incluso, antagonismos surgidos de la convivencia de equipos profesionales que suscriben a diferentes matrices: desde una perspectiva instrumental y funcionalista (confían en que los conocimientos e incorporación de TIC por sí mismos podrían garantizar resultados positivos en los procesos de enseñanza y aprendizaje, y además, por lo general, controlan estos equipamientos), a equipos que promueven una perspectiva crítica de los vínculos de la comunicación y pedagógicos, y advierten la necesidad de interpelar en estas modalidades virtuales al propio dispositivo, a fin de que el saber técnico no obture ni suprima el valor vivificante de la mediación pedagógica docente-tutor/docente-cursante; esto se da entre los colegas cursantes y otros espacios de instalación de este dispositivo.

El dispositivo tecnológico se sostiene en una cierta ilusión de control, mientras que el discurso pedagógico se funda en la consideración de que en los procesos de enseñanza y aprendizaje en cualquier entorno siempre algo escapa al control. También debe considerarse que el desarrollo de prácticas de enseñanza y aprendizaje en modalidades virtuales configura un territorio novedoso para los y las docentes, para muchos de los cuales el PNFP fue su primera experiencia.

Por otra parte, en la cadena significante del discurso oficial que modela el nuevo dispositivo político pedagógico actual y las subjetividades que éste propone, los términos "calidad", “innovación", "educación 3.0", "evaluación", e incluso "aprendizaje", "mediación pedagógica” y "conocimiento" se han ido constituyendo como significantes que deben ser necesariamente teorizados dentro de un marco y una contextualización política que no es posible desarrollar acá, pero sí señalar que están significando cosas muy distintas. Por ahora, basta con con decir que la relectura que propone Agamben de la definición de dispositivo foucaltiana puede servir de anclaje:

Lo que define los dispositivos que encontramos en la fase actual del capitalismo es que ellos no actúan tanto a través de la producción de un sujeto, sino a través de procesos que 
podemos llamar de desubjetivación. Es cierto que en todo proceso de subjetivación estaba implícito un momento desubjetivante y el Yo penitencial se constituía, como vimos, a través de su propia negación, pero lo que sucede ahora es que los procesos de subjetivación y los procesos de desubjetivación parecen volverse recíprocamente indiferentes y sólo dar lugar a la recomposición de un nuevo sujeto de forma larvada y, por así decir, espectral (Agamben, 2016: 28).

Si Agamben está en lo cierto y su hipótesis puede trasladarse a nuestra contingencia en materia de políticas de capacitación docente, si es que estamos frente a la constitución de un dispositivo desubjetivante, ¿seremos capaces de propiciar mutaciones, de descender a las Capadocias marechalianas y emerger nuevamente a las superficies? ¿Es posible que el espectro cobre (o recupere) la vida, con todo su potencial humanizante y humanizado, tal como lo concibieron las pedagogías emancipatorias? Algo que debe ser analizado en el futuro con mayor profundidad y sólo se menciona a título ilustrativo, es el problema de la apropiación de ciertos significantes discursivos del campo educativo que podemos denominar popular, emancipatorio, en la configuración del discurso neoliberal. Tal es el caso, por ejemplo, del uso del nombre "Freire", devenido en significante en cadenas discursivas -aparece en citas descontextualizadas, se le atribuyen determinados enunciados e ideas como artilugios de desconstrucción de sentido, de despolitización del discurso freireano, o bien, se lo deshistoriza, ignorando expresamente la propia revisión permanente de sus ideas que este intelectual va realizando a lo largo de su vida y de la asunción de distintos compromisos políticos y responsabilidades en la función pública, en el ámbito académico. Freire, las más de las veces, queda reducido a una suerte de significante que equivale a Freire = método de alfabetización de adultos, como si su aporte al campo pedagógico se redujera a un artefacto mecánico, a una técnica o una didáctica de la enseñanza de la escritura y la lectura que desconoce la problematización de la acción política que le atribuye a la educación, la crítica que realiza a las teorías reproductivistas, la relectura que hace del valor del reconocimiento como capital emancipatorio, de los vínculos entre comunicación y educación; del rol estratégico de la educación como herramienta de transformación política para los oprimidos pero de su crítica al llamado "educacionismo", que, por otra parte, hoy revive y goza de una extraordinaria vivificación en el discurso neoliberal, el discurso del poder. Se trata, en cierta forma, de la transposición de una serie de términos, de construcciones gramaticales, que son, cuanto menos, propias del siglo XIX y comienzos del XX, cuando todavía la idea de progreso y evolución no había sido interrumpida por las tragedias que, en Benjamin, se simbolizan en Auschwitz, y en nuestros países latinoamericanos, en el terrorismo de Estado con todo su orden de violencia, despojos y destrucción. 


\section{Maestros y profesores del siglo XXI}

Las experiencias de capacitación docente desarrolladas en los últimos años en el Instituto Nacional de Formación Docente (INFD), creado a posterior de la sanción de la Ley 26.206/06, en 2007, permiten suponer que el sujeto docente, más allá de mitos y discursos oficiales, es muy diferente al que estos imaginarios sostienen. Por lo pronto, hablamos de un millón de trabajadores de la educación radicados y enseñando y aprendiendo en muy diversas condiciones en las 24 jurisdicciones: hablamos de jóvenes que están aún transitando su formación de grado a la vez que se incorporan a las aulas, hasta profesores con mucha experiencia y formación superior universitaria. Hablamos de sujetos múltiples que enseñan arte, educación física, literatura, informática, matemática, expresión corporal, geografía, guaraní, inglés, portugués, instrumentos musicales, en medios rurales, en contextos de encierro, en islas, en grandes conglomerados urbanos, en escuelas plurigrados. En edificios nuevos y equipados con bibliotecas y laboratorios, con aulas informáticas, y en containers o edificios precarios y riesgosos. Hablamos de trabajar con lo que Carballeda (2008) denomina el "sujeto pedagógico inesperado", con poblaciones altamente vulneradas (y entonces, vulnerables), con familias que sufren violencia de género, injusticia social, hambre. Y también con maestros y maestras que enseñan en escuelas con poca matrícula, en comunidades con problemáticas diversas.

Como señala la pedagoga Adriana Puiggrós, "educar es una tarea imposible", en el sentido del psicoanálisis. "En un discurso educacional nunca coinciden lo enseñado y lo aprendido. El desplazamiento del saber transmitido por el educador y del saber construido por el educando deja abierta una fisura que hace posible la reproducción ampliada o la transformación de la cultura" (Puiggrós, 2017: 97). Dentro del aula, ya sea en la modalidad virtual o presencial, cada educador y educadora, cada grupo de estudiantes y docentes, produce sus propios vínculos pedagógicos que se desarrollan de manera diferente a toda previsión y planificación, precisamente porque educar y comunicar son actividades esencialmente humanas y humanizantes. Ahí está ese plus, eso que no es decible. Ese momento en donde puede haber, y lamentablemente hay, vínculos autoritarios, relaciones injustas, disciplinamiento, violencia, pero también vínculos dialógicos, en el sentido freireano. Si Freire se aparta de las teorías reproductivistas, si polemiza con Illich, es precisamente porque rescata la importancia de enseñar como un proceso complejo y una actividad política transformadora, sostiene que ese vínculo de enseñanza/aprendizaje no ocurre en el vacío, no es una mera reproducción de la ideología dominante.

Ahora bien, estos maestros contemporáneos, los mismos que aparecen en discursos mediáticos denigrados y estigmatizados muchas veces, han sido sujetos de las políticas públicas en los últimos años y miles de ellos se han formado y se han capacitado, (8) han 
luchado por hacerlo, están organizados sindicalmente en cada provincia y en una federación nacional como es Ctera, y que desde 1984 han demandado a los distintos gobiernos democráticos, antes y después de la reforma constitucional del 94, en el nivel provincial y nacional de acuerdo a las responsabilidades y competencias, capacitarse de manera gratuita, con puntaje, con una formación de calidad, permanente y en servicio. Quienes pretenden reducir las luchas docentes, desde aquella emblemática Carpa Blanca de los 90 a la Escuela Itinerante de la actualidad, a un reclamo salarial, o bien faltan a la verdad por especulación política o bien la desconocen.

Estas políticas públicas federales de capacitación permanente instrumentadas por el INFD, cuyo resultado fue el Programa Nacional de Formación Permanente (PNFP) "Nuestra Escuela", implican la construcción de fuertes acuerdos políticos con amplios sectores en los que participaron el gobierno nacional, los gobiernos provinciales, universidades nacionales, y se dio en el marco del acuerdo paritario con los sindicatos docentes con representación nacional, y una legalidad y legitimidad sin precedentes, que puede sintetizar así:

-Plan Nacional de Formación Docente: establecido mediante Resolución del Consejo Federal de Educación (CFE) Nro. 23/07), "brindó un marco al diseño e implementación de las políticas públicas en este campo. Se elaboró como resultado de un proceso de construcción colectiva que incorpora la experiencia y visión de las gestiones jurisdiccionales de educación superior, de equipos directivos y docentes de instituciones de gestión estatal y privada, como también de representantes de gremios docentes y de educadores". A este lo seguirán el Plan Nacional de Formación Docente 2012-2015 (Res. CFE Nro. 167/12) y luego, tras un consenso generado por las 25 jurisdicciones educativas (la Nación y las 24 provincias), en diciembre de 2012, se aprobó el Plan Nacional de Educación Obligatoria y Formación Docente 2012-2016 (Res. CFE Nro. 188/12).

\section{Conclusiones provisorias para continuar el debate}

Por diversas cuestiones que no se desarrollarán acá, la relación conflictiva entre escuela y tecnologías de la comunicación -se aclara ya que la propia escuela puede ser y es con frecuencia considerada como una tecnología de alfabetización- parece haber quedado en el pasado, aunque algunos de los trasfondos de los debates que originaron el conflicto se han reactualizado. Si los discursos pedagógicos, si la escuela, rechazó la incorporación de la televisión en su momento, y más adelante la de las por entonces llamadas nuevas tecnologías, ese rechazo expresaba de algún modo diversas posiciones: por un lado, porque se consideraba a las tecnologías como parte de una matriz exterior, una matriz colonizadora, que 
enajena las posibilidades de desarrollo nacionales y latinoamericanos. A su vez, hubo sectores que fueron seducidos por la "panacea tecnocrática" (Puiggrós, 2017: 23), y de este modo "la reflexión crítica" y la política se subordinan a la racionalidad tecnocrática, sostenida en la creencia de que la tecnología por sí sola puede transformar la educación. Atento a la potencia de esos discursos, que operan como cantos de sirenas seduciendo a educadores y educadoras, es que Jorge Huergo, referente indiscutido de este campo, le dedica especial atención en su último libro, La educación y la vida. Un libro para educadores populares y maestros de escuela (2015). Aquel discurso que propicia la idea de la innovación y el desarrollismo que proponía la Alianza para el Progreso está en los orígenes de la vinculación comunicación/educación, pues el campo está:

\footnotetext{
naciendo en este clima cultural ideológico, y está marcando a fuego las prácticas, de modo que hasta la actualidad persiste la ideología que impregnó este tipo de perspectivas y estrategias. Subyace en esta vinculación la teoría de la difusión de innovaciones, incluso en educación. Cargan las prácticas educativas con una nueva representación y una nueva demanda la adopción de las innovaciones, la modernización del paisaje educativo, construirá a una mejora de la calidad educativa (Huergo, 2017: 87).
}

Estos elementos propios de una época donde el Alianza para el Progreso tiene por objetivo frenar en el continente cualquier proceso similar a la revolución cubana, nuestra actualidad, con el declive -al menos transitoriamente-de los gobiernos populistas y la re-instauración neoliberal, emerge este discurso resignificado por nuevos elementos que en cierta forma, lo cambian todo: la omnipresencia del mercado. Si la Argentina estaba logrando, Arsat y Conicet mediantes, la posibilidad de producir ciencia y tecnologías como bienes sociales y públicos, la tecnocracia instrumental y sus discursos, como dispositivos del neoliberalismo, nos confrontan con un escenario aterrador. Es lo que Agamben enuncia como "dispositivos de desubjetivación". Si el dispositivo es configurador de sujetos,

Lo que define los dispositivos que encontramos en la fase actual del capitalismo es que ellos no actúan tanto a través de la producción de un sujeto, sino a través de procesos que podemos llamar de desubjetivación. Es cierto que en todo proceso de subjetivación estaba implícito un momento desubjetivante y el Yo penitencial se constituía, como vimos, a través de su propia negación, pero lo que sucede ahora es que los procesos de subjetivación y los procesos de desubjetivación parecen volverse recíprocamente indiferentes y sólo dar lugar a la recomposición de un nuevo sujeto de forma larvada y, por así decir, espectral (Agamben, 2016: 28). 
El escenario actual es complejo. La educación ha incorporado en mayor o menor medida las TIC, los cambios en los modos de enseñanza y aprendizaje que esto conlleva, con los profundos cambios en las lógicas de propiedad intelectual, de escritura, de lectura, de producción, circulación, edición de textos y contenidos multimediales, las herramientas didácticas disponibles, con la posibilidad del trabajo colaborativo en modalidades virtuales, 0 semipresenciales. En las políticas públicas para la capacitación docente desarrolladas en los últimos años se están incorporado a los debates y los discursos un pensar en clave de mutaciones la incorporación sucesiva y continua de dispositivos y su impacto los modos de comunicarse, de vincularse entre sí y con el mundo del conocimiento, estos modos propios de aquellos que Baricco denomina los "bárbaros" (2008). Incluso, una de las más antiguas tecnologías de la comunicación/educación que incorporó desde sus inicios la escuela moderna, el libro, ha reconfigurado su valor, que hoy "reside en ofrecerse como un abono para una experiencia más amplia [...] los bárbaros utilizan el libro para completar secuencias de sentido que se han generado en otra parte" (Baricco, 2010: 67).

Muchos maestros y maestras han aprendido esto en su práctica áulica cotidiana. Han incorporado que para muchos de sus estudiantes -o para ellos mismos- las redes sociales, Facebook, Twitter, Instagram, Snapchat, entre otras-constituyen "una lógica relacional, un modo de vincularse con el mundo" (Peirone, 2010: 145) que están cambiando los modos en los que nos relacionamos, comunicamos y educamos. La educación, por supuesto, no es ajena al ordenamiento del tecno-poder global, de modo que la hegemonía que imponen los llamados gigantes de la comunicación, Google, Facebook, Microsoft, la atraviesan. Ya en 2007, la filóloga y filósofa francesa Barbara Cassin advierte en su libro Googléame. La segunda misión de los Estados Unidos acerca de las profundas transformaciones en los modos de construir y transmitir conocimiento que la lógica mercantil de Google propone:

\footnotetext{
Darle lo que usted demanda, por lo tanto también sólo lo que está en condiciones de demandar. No me buscarías sino me hubieses encontrado ya: de buena gana sostendría que el mercado, como la fe, es exactamente lo contrario de la educación. [...] Google puede educar su manera de preguntar, para que su pedido sea más apropiado a la manera en que funciona el motor y usted encuentre más rápido las respuestas que le interesan, pero no puede ni quiere educar su demanda ni su tipo de interés, sobre los cuales, por el contrario, se apoya para satisfacerlo mejor (Cassin, 2007: 72).
}

Pero, como nos enseñó Foucault, donde hay poder hay resistencias. ¿Qué clase de subjetividades propone Google? ¿Qué sujetos pedagógicos son los que están formándose allí, como consumidores del mercado? No ciertamente los que propone la pedagogía emancipadora latinoamericana, que de ningún modo hoy rechaza el uso de tecnologías, muy por el contrario. La tarea educativa habita el mundo y crea mundo, y en tal sentido puede ser considerada en sí 
misma una tecnología que incorpora a otras tecnologías, con distinto grado de articulaciones, resistencias y adecuaciones desde sus orígenes, desde la imprenta y la invención de los libros, a las TIC contemporáneas y las modalidades virtuales de enseñanza-aprendizaje.

Estar pensando (en gerundio) la pedagogía, la incorporación de tecnologías a la educación pública desde una perspectiva crítica a los modelos dominantes, supone reconocer que la pedagogía y la comunicación que estamos haciendo en América latina es siempre acción política, de modo que también es interpelar al poder y a los modos en que este actúa también en la distribución de los bienes simbólicos y tecnológicos, y las subjetividades que proponen estos dispositivos. Es acción política también (y reflexión acerca de esta) el modo en que analizamos aquella escena fundante de la dominación, como la nombra Adriana Puiggrós, por medio de la lengua del conquistador, la escena del Requerimiento mediante el cual el blanco ritualiza su dominio exigiendo al conquistado en una lengua que no conoce, en la lengua del imperio (¿hoy Google?), que consienta en su opresión, que consienta en educarse en esa lengua y en esa religión del imperio, o bien, será eliminado no sólo en su cultura sino también en su cuerpo. El disciplinamiento de los cuerpos y de la lengua, repetido y resignificado en todas las formas de opresión, pero también resistido y denunciado en todas las formas de resistencia, puede leerse en una línea imaginaria que conecta el pensamiento del maestro de Simón Bolívar, Simón Rodríguez, con el de Francisco Gutiérrez que enfatiza: "la capacidad de los nuevos equipamientos culturales, en cuanto a la producción de disposiciones subjetivas y perceptivas (Gutiérrez, 1975: 141) y, a la vez, la articulación de esa relación con el reforzamiento de la dominación (Huergo, 2015: 209).

$\mathrm{Ni}$ los medios de comunicación ni las escuelas, ni las universidades, entonces, pueden contribuir a formar sujetos libres, ciudadanos plenos, críticos, en la medida en que no pertenezcan a las comunidades, a los pueblos, sino a los monopolios del capital transnacional. El imperio hoy es el mercado, amorfo, difuso y a la vez, omnipresente, y si el Estado abandona sus controles, sus dispositivos de resistencia, si se humilla y acepta el requerimiento de someterse a las reglas de juego del conquistador incluso sin entender su lengua ¿qué clase de comunicación/educación tendrán a disposición nuestros pueblos?

\section{Agradecimientos}

Le agradezco a Adriana Puiggrós la lectura crítica y los generosos e invaluables aportes a este artículo, y a Elvira Romera sus valiosas sugerencias.

\section{Notas}


(1) Durante la gestión de Adriana Puiggrós como Directora General de Cultura y Educación de la provincia de Buenos Aires, 2005-2007.

(2) Cuando en este texto se dice "educación o escuela pública", se entiende en un sentido amplio: con referencia a todas las instituciones educativas formales (de gestión estatal y a las de gestión privada de la educación obligatoria); desde el Nivel Inicial al Nivel Superior, de las diversas modalidades que configuran nuestro sistema federal.

(3) Aunque no está cerrada, la cifra estimada de cursantes de todos los postítulos a marzo de 2017 era de 340.000.

(4) Desde Simón Rodríguez a José Carlos Mariátegui, Elizardo Pérez, Julio Barcos, Virginia Bolten, la Teología de la Liberación, Freire, Saúl Taborda, entre otros.

(5) Estas acciones, además, se realizan utilizando mecanismos de despido ("no renovación de contratos") con modalidades que lesionan no solo los bolsillos sino también la dignidad y profesionalismo de los docentes formadores que desempeñaban roles de tutores, coordinadores, entre otros.

(6) La solidez de la arquitectura legal en la que se sostuvo el PNFP impidió o limitó que se lo diera de baja al inicio de la gestión de Cambiemos en diciembre de 2015, y limitó nuevamente esa iniciativa tomada mediante Decreto en las vísperas de la Nochebuena en 2016, cuando mediante el Boletín Oficial se comunicaba del cambio de régimen de regularidad para los 300 mil cursantes, y, en consecuencia, la baja de los postítulos y la pérdida de las fuentes laborales para los 2.600 docentes tutores, coordinadores, responsables de contenidos, webmaster, así como para unos 400 trabajadores de las áreas administrativas del MEyD. La rápida y organizada respuesta de los trabajadores y cursantes -que llevaron adelante varias acciones como el Abrazo al Ministerio, clases públicas, concurrencia y denuncia a medios de comunicación, entre otras-, en especial aquellos organizados en Ctera y ATE, así como la solidez del dispositivo legal del PNFP, impidieron que se materializara esa medida.

(7) Aún en esta final de los Postítulos del Programa Nacional de Formación Docente "Nuestra Escuela", la cifra de 340.000 docentes capacitándose y capacitados en el componente 2 del programa no tiene precedentes en la historia y posiblemente, tampoco en la región.

(8) Si bien aún no está incorporado en el DRAE, que admite tutorizar y tutorar, preferimos esté lexema que ha sido incorporado a numerosos textos académicos y especializados de esta manera, que es la de uso más frecuente en Argentina y la región y cumple con las normas "al formar el lexema tutor + el sufijo -ear, que forma verbos derivados de sustantivos o adjetivos, como humear, tutear, liderear, tuitear...", Cfr. en http://www.fundeu.es/noticia/de-tutorartutorizar-y-tutorear/

\section{Bibliografía}

Agamben, G. (2016). Qué es un dispositivo. Argentina: Adriana Hidalgo.

Alemán, J. (5 de junio de 2017). ¿Qué es la subjetivación neoliberal? Página/12. Recuperado de https://www.pagina12.com.ar/42162-que-es-la-subjetivacion-neoliberal

Baricco, A. (2010). Los bárbaros. Ensayo sobre la mutación. Buenos Aires: Selección, Anagrama, Página/12.

Byung-Chul, H. (2013). La sociedad de la transparencia. España: Herder.

Carballeda, A. (2008). La Intervención en lo Social y las Problemáticas Sociales Complejas: los escenarios actuales del Trabajo Social. Periódico de Trabajo Social y Ciencias Sociales (edición digital), $48 . \quad$ Recuperado de https://www.margen.org/suscri/margen48/carbal.html 
Cassin, B. (2007). Googleame. La segunda misión de los Estados Unidos. Buenos Aires: FCE.

De Alba, A. (1991). Evaluación curricular. Conformación conceptual del campo. México: Unam.

Freire, P. (1970). Pedagogía del oprimido. Buenos Aires: Siglo XXI.

Gessaghi, V. (2016). La educación de la clase alta argentina. Entre la herencia y el mérito. Buenos Aires: Siglo XXI.

Groys, B. (2016) Arte en flujo. Ensayos sobre la evanescencia del presente. Buenos Aires: Caja negra.

Huergo, J. (2015). La educación y la vida. Un libro para maestros de escuela y educadores populares. La Plata: Ediciones de Periodismo y comunicación.

Martin-Barbero, J. (octubre de 2017). Saberes hoy: diseminaciones, competencias y transversalidades. OEI-Revista Iberoamericana de Educación, 32. Recuperado de https://rieoei.org/RIE

Merklen, D. (2013). Bibliotecas en llamas. Cuando las clases populares cuestionan la sociología y la política. Los Polvorines, provincia de Buenos Aires: Ediciones UNGS.

Peirone, F. (2010). Educación extensa. En La educación alterada. Aproximaciones a la escuela del siglo XXI. Villa María, Córdoba: Eduvim.

Pineau, P. (2011). ¿Por qué triunfó la escuela? o la modernidad dijo: ‘Esto es la educación', y la escuela respondió: 'Yo me ocupo'". En La escuela como máquina de educar. Tres escritos sobre un proyecto de la modernidad. Buenos Aires: Paidós.

Puiggrós, A. (2017). Adiós Sarmiento. Educación pública, Iglesia y mercado. Buenos Aires: Colihue. 